\title{
Multicenter phase II study of weekly paclitaxel plus S-1 combination chemotherapy in patients with advanced gastric cancer
}

\author{
Yuji Ueda ${ }^{1,2}$, Hisakazu Yamagishi ${ }^{1}$, Daisuke Ichikawa ${ }^{1}$, Kazuma Okamoto $^{1}$, Eigo Otsuji ${ }^{1}$, Jun Morir $^{3}$, \\ Kinya Koizumi $^{3}$, Naoki Kakihara ${ }^{4}$, Masataka Shimotsuma ${ }^{4}$, Tetsuro Yamashita ${ }^{5}$, Fumihiro Taniguchi, \\ Hideki Aragane ${ }^{6}$, Hiroshi Nishi ${ }^{7}$, Yoshiki Itokawa ${ }^{2}$, Satoshi Morita $^{8}$, and Junichi Sakamoto ${ }^{9}$ \\ ${ }^{1}$ Department of Surgery, Division of Digestive Surgery, Kyoto Prefectural University of Medicine, Kyoto, Japan \\ ${ }^{2}$ Department of Surgery, Nantan General Hospital, 25 Yagiueno, Yagi-cho, Nantan, Kyoto 629-0197, Japan \\ ${ }^{3}$ Department of Surgery, National Hospital Organization Kyoto Medical Center, Kyoto, Japan \\ ${ }^{4}$ Department of Surgery, Kyoto Second Red Cross Hospital, Kyoto, Japan \\ ${ }^{5}$ Department of Surgery, Kyoto First Red Cross Hospital, Kyoto, Japan \\ ${ }^{6}$ Department of Surgery, Aiseikai Yamashina Hospital, Kyoto, Japan \\ ${ }^{7}$ Department of Surgery, Saiseikai Kyoto Hospital, Kyoto, Japan \\ ${ }^{8}$ Department of Biostatistics and Epidemiology, Yokohama City University Medical Center, Kanagawa, Japan \\ ${ }^{9}$ Young Leaders' Program, Nagoya University Graduate School of Medicine, Aichi, Japan
}

\begin{abstract}
Background. A multicenter phase II study was conducted to evaluate the efficacy and safety of a combination regimen of weekly paclitaxel plus $S-1$ in patients with advanced gastric cancer.

Methods. Patients with previously untreated metastatic or recurrent gastric cancer received intravenous paclitaxel $50 \mathrm{mg} /$ $\mathrm{m}^{2}$ on days 1,8 , and 15 , plus oral $S-140 \mathrm{mg} / \mathrm{m}^{2}$ b.i.d. on days 1 to 14 followed by 2 weeks off, in a 28-day cycle.

Results. A total of 54 patients were registered. All of them had measurable disease and were determined to be eligible for the present study. Two complete responses and 23 partial responses were confirmed, giving an overall response rate of $46.3 \%$. At a final follow up of 3 years, the median progressionfree survival and median overall survival were 6.0 and 14.3 months, respectively. Grade 3 neutropenia occurred in 14 patients, and grade 4 in 1 patient (total, 27.8\%). The most serious nonhematological toxicity was diarrhea, where grade 3 occurred in 5 patients $(9.3 \%)$. There were no treatmentrelated deaths.

Conclusion. A combination of weekly paclitaxel plus S-1 was found to be well tolerated and effective in patients with advanced gastric cancer. Further investigation with comparative trials is needed for confirmation.
\end{abstract}

Key words Weekly paclitaxel $\cdot$ S- 1 - Phase II study $\cdot$ Gastric cancer

\section{Introduction}

Gastric cancer remains one of the most common causes of cancer-related deaths in the world [1]. Although the

Offprint requests to: Y. Ueda

Received: October 3, 2009 / Accepted: February 10, 2010 prognosis of advanced gastric cancer is still poor, chemotherapies were reported to improve the overall survival compared to the best supportive care in several studies [2-4]. Among the various active chemotherapeutic agents, cisplatin-based chemotherapy is the most commonly used worldwide. The V-325 study demonstrated that adding docetaxel (D) to a frequently used regimen of cisplatin and 5-fluorouracil (CF) provided benefits with regard to overall survival, response rate, time to disease progression, clinical benefit, and healthrelated quality of life [5]. Although the DCF regimen provides these advantages, it is accompanied by an increase in toxicity compared with the doublet regimen. The toxicity profile of DCF is acceptable only with appropriately selected patients and comprehensive toxicity management strategies [6]. In this regard, the development of less toxic new combination chemotherapy has still been considered necessary to properly treat those patients with advanced gastric cancer.

Paclitaxel, (Taxol; Bristol-Myers Squibb, Princeton, NJ, USA), which is derived from the bark of the Pacific yew, Taxus brevifolia, is one of the most active anticancer drugs for the treatment of solid tumors, effectively blocking cancer cells in the $\mathrm{G} 2 / \mathrm{M}$ phase through the inhibition of microtubular depolymerization $[7,8]$. An administration schedule at doses of $175-225 \mathrm{mg} / \mathrm{m}^{2}$ by intravenous infusion every 3 weeks has been widely accepted [9]. In addition, several phase II studies have shown that paclitaxel, alone or in combination with cisplatin or 5-fluorouracil (5-FU), is also active against advanced gastric cancer [10-13]. However, a relatively high incidence of grade 3 or 4 neutropenia $(14 \%-35 \%)$ is one of the major adverse effects.

Paclitaxel is known to be a cell-cycle-specific agent, and in vitro experiments have suggested that prolonged 
exposure to paclitaxel, through either continuous infusion schedules or weekly administration, can lead to enhanced cytotoxicity [14-16]. Furthermore, recent clinical studies have demonstrated that weekly schedules of intravenous paclitaxel have promising antitumor activity with tolerable safety profiles for several types of solid tumors, including lung, breast, and ovarian cancers $[17,18]$.

S-1 (TS-1; Taiho Pharmaceutical, Tokyo, Japan) is an oral pyrimidine fluoride-derived anticancer agent which is combined with two classes of modulators to enhance antitumor effects and decrease gastrointestinal toxicity $[19,20]$. The response rate after treatment with S-1 alone was $20 \%-50 \%$ in patients with advanced gastric cancer when it was administered for 4 weeks with 2 weeks off [21-25]. The main side effects of S-1 treatment were diarrhea, fatigue, anemia, and neutropenia.

Because paclitaxel has synergistic antitumor effects with 5-FU, according to clinical trials as well as preclinical studies, and it has a different spectrum of side effects from that of S-1, a combination of paclitaxel and S-1, one of the most potent fluorinated pyrimidines, was considered to be promising for the treatment of gastric cancer $[26,27]$. Several clinical trials of S-1 and paclitaxel combination therapy have been conducted in Japan [28-33]. The response rate has been reported to be $40 \%-60 \%$ with the schedule of S- $180 \mathrm{mg} / \mathrm{m}^{2}$ for 14 days plus paclitaxel $50-60 \mathrm{mg} / \mathrm{m}^{2}$ on days 1 and 8 or days 1 and 15 . We have also conducted a phase I clinical trial of 2 weeks S-1 plus weekly paclitaxel on days 1, 8, and 15 of a 4-week cycle [34]. Based on the data from that trial, a multicenter phase II study was conducted by the Kyoto Gastrointestinal Cancer Chemotherapy Study Group in order to assess the efficacy of S-1 and weekly paclitaxel administered every 4 weeks as firstline treatment for patients with advanced or metastatic gastric cancer.

\section{Patients and methods}

\section{Eligibility}

All patients registered in the present study had histologically confirmed advanced or recurrent gastric cancer - (1) gastric adenocarcinoma diagnosed by endoscopic biopsy, or (2) unresectable metastatic or recurrent tumors diagnosed by clinical findings. The primary endpoint of this study was the objective response rate induced by treatment with weekly paclitaxel plus S-1 in these patients. Eligibility criteria consisted of at least one unidimensionally measurable lesion (i.e., diameter $\geq 1 \mathrm{~cm}$, as assessed by spiral computed tomography). The patients were 20-80 years of age with a performance status of $0-2$ on the Eastern Cooperative Oncology Group (ECOG) scale. Plus, adequate hematological (absolute neutrophil count $\geq 1.5 \times 10^{9} / 1$, platelet count $\geq$ $100 \times 10^{9} / 1$, hemoglobin $\geq 9 \mathrm{~g} / \mathrm{dl}$ ), renal (serum creatinine $\leq 1.5 \mathrm{mg} / \mathrm{dl}$ and creatinine clearance $\geq 50 \mathrm{ml} / \mathrm{min}$ ), and hepatic (total bilirubin $\leq 2.0 \mathrm{mg} / \mathrm{dl}$ and serum transaminase level $\leq 3$ times the upper limit of the normal range) levels were also required. Patients who had received adjuvant chemotherapy using neither taxanes nor S-1, completed 4 weeks before entry, were eligible. Patients were ineligible if they had previously received palliative chemotherapy or radiation therapy, or had other severe medical illnesses, central nervous system (CNS) metastasis, another active malignancy, or a history of anaphylactic reaction to drugs. The institutional review board of each author's institution approved the protocol, and written informed consent was obtained from all patients before enrollment.

\section{Treatment plan and dose modification}

Paclitaxel, $50 \mathrm{mg} / \mathrm{m}^{2}$, was administered through a $1-\mathrm{h}$ intravenous infusion on days 1,8 , and $15 . \mathrm{S}-1,40 \mathrm{mg} / \mathrm{m}^{2}$ b.i.d. ( $80 \mathrm{mg} / \mathrm{m}^{2}$ per day), was administered for 14 consecutive days. The chemotherapy was given in a 4-week cycle and was continued until disease progression, patient refusal, or the occurrence of an unacceptable toxicity. All patients were premedicated with a dexamethasone $20 \mathrm{mg}$, ranitidine $150 \mathrm{mg}$, and diphenhydramine $50 \mathrm{mg}$ intravenous injection $30 \mathrm{~min}$ before paclitaxel administration to prevent hypersensitivity reactions. Granulocyte colony-stimulating factor was permitted if a patient developed grade 4 neutropenia; primary prophylaxis was not allowed. Antiemetic treatment was allowed at the discretion of the treating physician.

Adverse events were graded according to National Cancer Institute Common Toxicity Criteria (NCI-CTC) version 3.0. The dose of S-1 was to be reduced to $50 \mathrm{mg} /$ $\mathrm{m}^{2}$ per day in the event of any of the following toxicities occurring during the previous treatment cycle: grade 4 leukopenia or neutropenia; grade 3 febrile neutropenia; thrombocytopenia $\geq$ grade 3 ; and nonhematological toxicity $\geq$ grade 3 , except for anorexia, nausea, and vomiting. There were no dose reductions for paclitaxel. The next course of treatment was only allowed to begin when the neutrophil count was $\geq 1.5 \times 10^{9} / 1$, platelet count was $\geq 100 \times 10^{9} / 1$, and any other treatment-related toxicities were less than or equal to grade 1 ; otherwise, treatment was withheld for up to 2 weeks. If adverse events did not improve to grade 0 or 1 after 2 weeks, the patients were excluded from the study.

\section{Study assessments}

A screening assessment, including a medical history, physical examination, ECG, chest X-ray, and tumor 
assessment, was conducted within 2 weeks before the patient started treatment. Further assessments, conducted within 7 days before starting treatment, included vital signs, ECOG performance status, and laboratory tests. Complete blood counts were performed weekly during the first cycle and every cycle thereafter, and biochemical tests were performed before each cycle. Tumor markers, including carcinoembryonic antigen and carbohydrate antigen (CA) 19-9, were also monitored before each cycle. Tumors were measured every two cycles until the tumor progressed. The tumor responses were classified according to the response evaluation criteria in solid tumors (RECIST) guidelines [35]. Patients with a complete response (CR) or partial response $(\mathrm{PR})$ required a confirmatory disease assessment at least 4 weeks later.

\section{Statistical analysis}

The present trial used a two-stage optimal design, as proposed by Simon, with an $80 \%$ power to accept the hypothesis and $5 \%$ significance to reject the hypothesis [36]. Plus, the present trial was designed to detect a response rate of $40 \%$ as compared to a minimal, clinically meaningful response rate of $20 \%$. Allowing for a follow-up loss rate of $10 \%$, the total sample size was 48 patients with a measurable disease. All enrolled patients were included in the intention-to-treat analysis of efficacy. The duration of response, time to progression (TTP), and survival analyses were all estimated using the Kaplan-Meier method. The duration of response was defined as the interval from the onset of a CR or PR until evidence of disease progression was found. Meanwhile, the TTP was calculated from the initiation of chemotherapy to the date of disease progression, while overall survival was measured from the initiation of chemotherapy to the date of the last follow up or death. The data were analyzed statistically using an SPSS software package (SPSS 11.0; SPSS, Chicago, IL, USA).

\section{Results}

\section{Patient characteristics}

From November 2003 to November 2005, a total of 54 patients were registered. All of them had "measurable disease" by the RECIST criteria and were determined to be eligible for the present study. The median age was 61 years (range, 38-78 years), with 42 males and 12 females. Most of the patients $(98.1 \%)$ had a good performance status (ECOG 0 or 1). Thirty-nine (72.2\%) patients had a metastatic disease, while 15 patients had a recurrent disease after surgical resection (total or sub-
Table 1. Patient characteristics $(n=54)$

\begin{tabular}{ll}
\hline Sex (male/female) & $42(78 \%) / 12(22 \%)$ \\
Age, years, median (range) & $61(38-78)$ \\
PS (0/1/2) & $47 / 6 / 1$ \\
Resected primary tumor (yes/no) & $15 / 39$ \\
Histology (differentiated/ & $27 / 27$ \\
$\quad$ undifferentiated) & \\
Metastatic sites & \\
$\quad$ Lymph node & 44 \\
$\quad$ Liver & 16 \\
$\quad$ Lung & 2 \\
$\quad$ Peritoneum & 1 \\
$\quad$ Total & 268 \\
No. of treatment cycles & \\
$\quad$ Median & 5.0 \\
Range & $1-14$
\end{tabular}

PS, performance status

Table 2. Best overall response $(n=54)$

\begin{tabular}{lc}
\hline Complete response (CR) & 2 \\
Partial response (PR) & 23 \\
Stable disease (SD) & 21 \\
Progressive disease (PD) & 6 \\
Not evaluable (NE) & 2 \\
Response rate (RR) & $25 / 54(46.3 \%)$ \\
Liver & $8 / 16(50.0 \%)$ \\
Lymph node & $21 / 44(47.7 \%)$ \\
Lung & $1 / 2(50.0 \%)$ \\
\hline
\end{tabular}

total gastrectomy) of the primary tumor. Distal lymph nodes and the liver were the most common sites of the metastases (Table 1).

\section{Response and survival}

Among the 54 patients who received the combination chemotherapy, 2 patients were not evaluable for response owing to early dropout in the middle of the first cycle of chemotherapy; these 2 patients withdrew their consent. Two cases of CR and 23 cases of PR were confirmed, giving an overall response rate of $46.3 \%$ according to an intent-to treat analysis. The response characteristics are shown in Table 2. Complete responses were observed in a patient with liver metastases and a patient with lymph node metastases. The median progression-free survival for all the patients was 6.0 months (95\% confidence interval [CI], 4.7-8.4 months) at the final follow-up duration of 36 months (Fig. 1). More than half of the patients received second-line therapies including agents such as irinotecan or cisplatin after disease progression. Twenty-five patients had died at the time of the present evaluation. The estimated median overall survival was 14.3 months (95\% CI, 12.1-17.4 months) with an estimated 1-year survival rate of $64.2 \%$ (Fig. 2). 


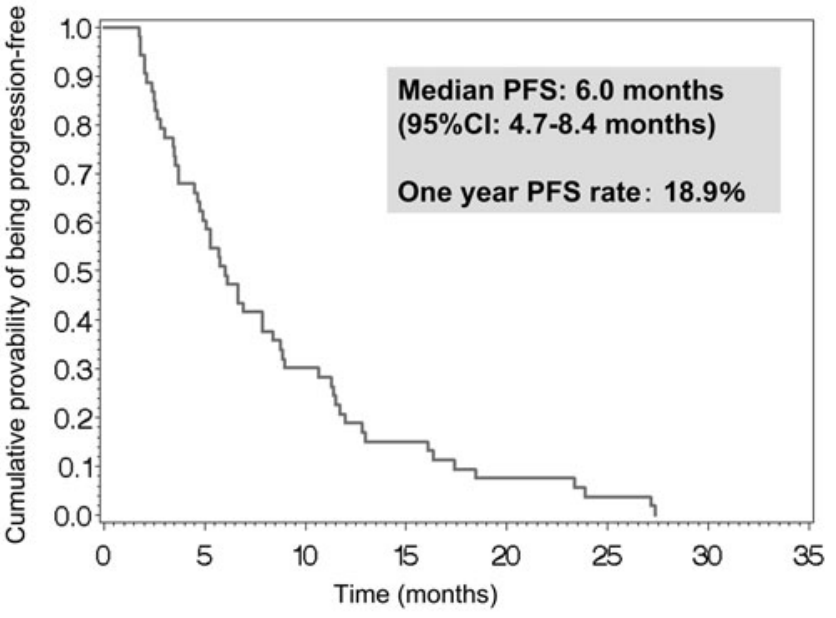

Fig. 1. Kaplan-Meier plot of progression-free survival (PFS)

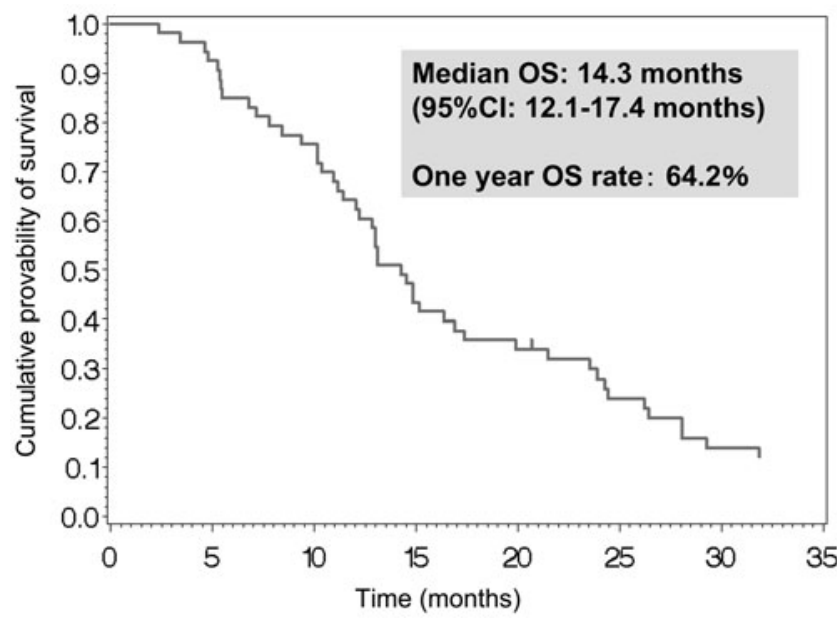

Fig. 2. Kaplan-Meier plot of overall survival $(O S)$

\section{Toxicity}

The hematological and nonhematological toxicities that occurred during the present study are summarized in Table 3. A total of 268 cycles (median, 5; range, 1-14) were administered in the 54 patients assessable for toxicity. The most frequently observed severe hematological adverse event was neutropenia, which occurred with grade 3 intensity in 14 patients $(25.9 \%)$ and in 27 cycles $(10.1 \%)$. In addition, grade 4 neutropenia was observed in 1 patient. Grade 3 anemia was observed in 7 patients $(13.0 \%)$. Thrombocytopenia $\geq$ grade 3 was not observed. Nonhematological toxicities were generally mild in severity and no grade 4 cases were observed. The most common grade 3 nonhematological toxicities were diarrhea $(9.3 \%)$, anorexia $(7.4 \%)$, and nausea $(7.4 \%)$, but no grade 4 nonhematological toxicity was observed. Four patients $(7.4 \%)$ were hospitalized due to treatment toxicities ( 1 due to neutropenia and 3 due to
Table 3. Toxicity $(n=54)^{\mathrm{a}}$

\begin{tabular}{lrrrrc}
\hline & \multicolumn{5}{c}{ Grade } \\
\cline { 2 - 6 } Type & 1 & 2 & 3 & 4 & 3 and $4(\%)$ \\
\hline Hematological & & & & & \\
$\quad$ Leukopenia & 12 & 19 & 5 & 0 & 9.3 \\
Neutropenia & 5 & 8 & 14 & 1 & 27.8 \\
Anemia & 24 & 18 & 7 & 0 & 13.0 \\
Thrombocytopenia & 17 & 2 & 0 & 0 & 0 \\
Nonhematological & & & & & \\
Anorexia & 19 & 6 & 4 & 0 & 7.4 \\
Nausea & 18 & 4 & 4 & 0 & 7.4 \\
Vomiting & 4 & 1 & 1 & 0 & 1.8 \\
Stomatitis & 3 & 4 & 2 & 0 & 3.7 \\
Diarrhea & 7 & 4 & 5 & 0 & 9.3 \\
Fatigue & 20 & 6 & 2 & 0 & 3.7 \\
Alopecia & 24 & 1 & - & - & -1.8 \\
Allergic reaction & 2 & 0 & 1 & 0 & 0 \\
Neuropathy & 3 & 1 & 0 & 0 & 0 \\
Arthralgia & 3 & 1 & 0 & 0 &
\end{tabular}

${ }^{a}$ National Cancer Institute Common Toxicity Criteria (NCI-CTC) Ver. 3

general weakness); however, all treatment-related toxicities resolved with appropriate care and no treatmentrelated deaths occurred during this study. The dose of S-1 was reduced to $50 \mathrm{mg} / \mathrm{m}^{2}$ per day in 6 patients $(11.1 \%)$ and $16(6.0 \%)$ cycles according to the dose reduction criteria.

\section{Discussion}

Many clinical trials of S-1 plus other chemotherapeutic agents such as cisplatin or docetaxel have been carried out in patients with gastric cancer [37-39]. Some promising results have been reported with response rates of $40 \%-70 \%$ and median survivals of $11-14$ months with these combination regimens. Among such trials, the SPIRITS randomized phase III trial recently verified that overall survival was better in patients treated with S-1 plus cisplatin than in those treated with S-1 alone [39]. Thus, an S-1 plus cisplatin regimen, which consists of oral S-1 ( $80 \mathrm{mg} / \mathrm{m}^{2}$ per day) for 3 consecutive weeks and intravenous cisplatin $\left(60 \mathrm{mg} / \mathrm{m}^{2}\right)$ on day 8 , is regarded as a standard treatment for gastric cancer in Japan now. However, although promising results were reported in such S-1 plus cisplatin combination trials, a significant level of grade 3-4 gastrointestinal toxicities occurred. For example, $30 \%$ of the patients in the SPIRITS trial experienced grade 3-4 anorexia, and almost all the patients needed short-term hospitalization for hydration to avoid renal toxicity caused by intravenous cisplatin $[38,39]$. As is well known, the final aim of cancer chemotherapy is to prolong the survival of patients with good quality of life (QOL), but 
these nonhematological toxicities spoil patients' QOL significantly.

In the present study, the weekly paclitaxel plus S-1 combination had very tolerable gastrointestinal toxicities as well as active antitumor effects. All grade 3-4 gastrointestinal toxicities, including anorexia, nausea, and diarrhea developed in fewer than $10 \%$ of the patients. The mild neurotoxicity, which was also reported by Kawabata et al. [31], could be attributable to the super-low dosage of paclitaxel in our regimen. In addition, the hematological toxicities in our present study were also milder than those observed in patients treated with cisplatin/S-1, docetaxel/S-1, or DCF [6, 37, 39]. These mild toxicities allowed more than half of the patients to receive second-line chemotherapies including agents such as cisplatin or irinotecan, and this may have contributed to enhancing the overall survival. Future studies are needed to determine which combination with S-1 would be best, on the basis of treatment efficacy and toxicity.

So far, two other phase II studies of weekly paclitaxel plus S-1 for gastric cancer that used the same schedule as ours (paclitaxel, 3 weeks on and 1 week off; S-1, 2 weeks on and 2 weeks off) have been reported. In these studies, Mochiki et al. used $60 \mathrm{mg} / \mathrm{m}^{2}$ weekly paclitaxel [32] and Kawabata et al. [31] used $50 \mathrm{mg} / \mathrm{m}^{2}$ weekly paclitaxel, which was the same dose as ours. Both of these groups reported response rates a little higher than ours and overall survivals similar to ours. However, their studies were combined phase I/II studies and the numbers of patients enrolled in the phase II portions were very small ( $n=18$ and $n=24$, respectively, in the two studies). Thus, our present study might be the most reliable phase II study of a weekly paclitaxel plus S-1 combination for gastric cancer.

In conclusion, the results of the present phase II study demonstrated that the combination of weekly paclitaxel plus S-1 was safe and effective, with a favorable toxicity profile. The present combination regimen at this schedule is a novel option for the initial treatment of patients with advanced or metastatic gastric cancer. Further investigation with comparative trials is needed for confirmation.

Acknowledgments This study was supported, in part, by a nonprofit organization: the Epidemiological \& Clinical Research Information Network (ECRIN).

\section{References}

1. Velde C, Peeters K. The gastric cancer treatment controversy. J Clin Oncol 2003;21:2234-6.

2. Murad AM, Santiago FF, Petroianu A, Rocha PR, Rodrigues MA, Ransch M. Modified therapy with 5-fluorouracil, doxorubicin, and methotrexate in advanced gastric cancer. Cancer 1993;72:37-41.
3. Pyrhonen S, Kuitunen T, Nyandoto P, Kouri M. Randomized comparison of fluorouracil, epidoxorubicin and methotrexate (FEMTX) plus supportive care with supportive care alone in patients with non-resectable gastric cancer. Br J Cancer 1995;71: 587-91.

4. Glimelius B, Hoffmann K, Haglund U, Nyron O, Sjoden PO. Initial or delayed chemotherapy with best supportive care in advanced gastric cancer. Ann Oncol 1994;5:189-90.

5. Ajani JA, Moiseyenko VM, Tjulandin S, Majlis A, Constenla M, Boni C, et al. Clinical benefit with docetaxel plus fluorouracil and cisplatin compared with cisplatin and fluorouracil in a phase III trial of advanced gastric cancer or gastroesophageal adenocarcinoma: the V-325 study group. J Clin Oncol 2007;25:3205-9.

6. Ajani JA, Moiseyenko VM, Tjulandin S, Majlis A, Constenla M, Boni C, et al. Quality of life with docetaxel plus cisplatin and fluorouracil compared with cisplatin and fluorouracil from a phase III trial for advanced gastric or gastroesophageal adenocarcinoma: the V-325 study group. J Clin Oncol. 2007;25:3210-6.

7. Schiff PB, Fant J, Horwitz SB. Promotion of microtubule assembly in vitro by Taxol. Nature 1979;277:665-7.

8. Jordan MA, Wendell K, Gardiner S, Derry WB, Copp H, Wilson L. Mitotic block induced in HeLa cells by low concentrations of paclitaxel (Taxol) results in abnormal mitotic exit and apoptotic cell death. Cancer Res 1996;56:816-25.

9. Schiller JH, Harrington D, Belani CP, Langer C, Sandler A, Krook $\mathrm{J}$, et al. Comparison of four chemotherapy regimens for advanced non-small-cell lung cancer. N Engl J Med 2002;346:92-8.

10. Ajani JA, Fairweather J, Dumas P, Patt YZ, Pazdur R, Mansfield PF. Phase II study of Taxol in patients with advanced gastric carcinoma. Cancer J Sci Am 1998;4:269-74.

11. Bokemeyer C, Lampe CS, Clemens MR, Hartmann JT, Quietzsch D, Forkmann L, et al. A phase II trial of paclitaxel and weekly $24 \mathrm{~h}$ infusion of 5-fluorouracil/folinic acid in patients with advanced gastric cancer. Anticancer Drugs 1997;8:396-9.

12. Kollmannsberger C, Quietzsch D, Haag C, Lingenfelser T, Schroeder M, Hartmann JT, et al. A phase II study of paclitaxel, weekly, 24-hour continuous infusion 5-fluorouracil, folinic acid and cisplatin in patients with advanced gastric cancer. $\mathrm{Br} \mathrm{J}$ Cancer 2000;83:458-62.

13. Kim MK, Lee KH, Hyun MS, Do YR, Song HS, Lee WS, et al. A multi-center, phase II clinical trial of Padexol (paclitaxel) and cisplatin for patients suffering with advanced gastric cancer. Cancer Res Treat 2005;37:349-53.

14. Georgiadis MS, Russell EK, Gazdar AF, Johnson BE. Paclitaxel cytotoxicity against human lung cancer cell lines increases with prolonged exposure durations. Clin Cancer Res 1997;3:449-54.

15. Liebmann JE, Cook JA, Lipschultz C, Teague D, Fisher J, Mitchell JB. Cytotoxic studies of paclitaxel (Taxol) in human tumor cell lines. Br J Cancer 1993;68:1104-9.

16. Zhan Z, Scala S, Monks A, Hose C, Bates S, Fojo T. Resistance to paclitaxel mediated by P-glycoprotein can be modulated by changes in the schedule of administration. Cancer Chemother Pharmacol 1997;40:245-50.

17. Akerley W, Herndon JE, Egorin MJ, Lyss AP, Kindler HL, Savarese DM, et al. Weekly, high-dose paclitaxel in advanced lung carcinoma: a phase II study with pharmacokinetics by the Cancer and Leukemia Group B. Cancer 2003;97:2480-6.

18. Seidman AD, Hudis CA, Albanell J, Tong W, Tepler I, Currie V, et al. Dose-dense therapy with weekly 1 -hour paclitaxel infusions in the treatment of metastatic breast cancer. J Clin Oncol 1998; 16:3353-61.

19. Chu QS, Hammond LA, Schwartz G, Ochoa L, Rha SY, Denis L, et al. Phase I and pharmacokinetic study of the oral fluoropyrimidine S-1 on a once-daily-for-28-day schedule in patients with advanced malignancies. Clin Cancer Res 2004;10:4913-21.

20. Hoff PM, Saad ED, Ajani JA, Lassere Y, Wenske C, Medgyesy D, et al. Phase I study with pharmacokinetics of S-1 on an oral daily schedule for 28 days in patients with solid tumors. Clin Cancer Res 2003;9:134-42. 
21. Chollet P, Schoffski P, Weigang-Kohler K, Schellens JH, Cure H, Pavlidis N, et al. Phase II trial with S-1 in chemotherapy-naive patients with gastric cancer. A trial performed by the EORTC Early Clinical Studies Group (ECSG). Eur J Cancer 2003;39: 1264-70.

22. Jeung HC, Rha SY, Kim HK, Lim HY, Kim S, Kim SY, et al. Multiinstitutional phase II study of S-1 monotherapy in advanced gastric cancer with pharmacokinetic and pharmacogenomic evaluations. Oncologist 2007;12:543-54.

23. Koizumi W, Kurihara M, Nakano S, Hasegawa K. Phase II study of S-1, a novel oral derivative of 5-fluorouracil, in advanced gastric cancer. For the S-1 Cooperative Gastric Cancer Study Group. Oncology 2000;58:191-7.

24. Sakata Y, Ohtsu A, Horikoshi N, Sugimachi K, Mitachi Y, Taguchi T. Late phase II study of novel oral fluoropyrimidine anticancer drug S-1 (1 M tegafur-0.4 M gimestat-1 $\mathrm{M}$ otastat potassium) in advanced gastric cancer patients. Eur J Cancer 1998;34:1715-20.

25. Sugimachi K, Maehara Y, Horikoshi N, Shimada Y, Sakata Y, Mitachi Y, et al. An early phase II study of oral S-1, a newly developed 5-fluorouracil derivative for advanced and recurrent gastrointestinal cancers. The S-1 Gastrointestinal Cancer Study Group. Oncology 1999;57:202-10.

26. Kano Y, Akutsu M, Tsunoda S, Ando J, Matsui J, Suzuki K, et al. Schedule-dependent interaction between paclitaxel and 5-fluorouracil in human carcinoma cell lines in vitro. $\mathrm{Br} \mathrm{J}$ Cancer 1996;74:704-10.

27. Murad AM, Petroianu A, Guimaraes RC, Aragao BC, Cabral LO, Scalabrini-Neto AO. Phase II trial of the combination of paclitaxel and 5-fluorouracil in the treatment of advanced gastric cancer: a novel, safe, and effective regimen. Am J Clin Oncol 1999;22: 580-6.

28. Fujitani K, Narahara H, Takiuchi H, Tsujinaka T, Satomi E, Gotoh $\mathrm{M}$, et al. Phase I and pharmacokinetic study of S-1 combined with weekly paclitaxel in patients with advanced gastric cancer. Oncology 2005;69:414-20.

29. Fujiwara Y, Fujita J, Kan K, Tsukahara Y, Takiguchi S, Miyata H, et al. A phase I study of combination chemotherapy using TS-1 and weekly paclitaxel for advanced gastric cancer. Gan To Kagaku Ryoho 2006;33:45-8.

30. Hokita S, Aikou T, Miyazono F, Ishigami S, Aridome K, Maenohara S, et al. A phase I combination chemotherapy study of biweekly paclitaxel and S-1 administration in patients with advanced gastric cancer. Cancer Chemother Pharmacol 2006; 57:736-40.

31. Kawabata R, Fujiwara Y, Doki Y, Fujita J, Tsukahara Y, Yamasaki $\mathrm{M}$, et al. Phase I/II study of a combination of S-1 and weekly paclitaxel in patients with advanced or recurrent gastric cancer. Oncology 2007;72:219-25.

32. Mochiki E, Ohno T, Kamiyama Y, Aihara R, Haga N, Ojima H, et al. Phase I/II study of S-1 combined with paclitaxel in patients with unresectable and/or recurrent advanced gastric cancer. Br J Cancer 2006;95:1642-7.

33. Nakajo A, Hokita S, Ishigami S, Miyazono F, Etoh T, Hamanoue $\mathrm{M}$, et al. A multicenter phase II study of biweekly paclitaxel and S-1 combination chemotherapy for unresectable or recurrent gastric cancer. Cancer Chemother Pharmacol 2008;62:1103-9.

34. Ueda Y, Yamagishi H, Ichikawa D, Morii J, Koizumi K, Kakihara $\mathrm{N}$, et al. Phase I study of a combination of S-1 and weekly paclitaxel in patients with advanced or recurrent gastric cancer. Oncology 2005;69:261-8.

35. Therasse P, Arbuck SG, Eisenhauer EA, Wanders J, Kaplan JS, Rubinstein L, et al. New guidelines to evaluate the response to treatment in solid tumors. European Organization for Research and Treatment of Cancer, National Cancer Institute of the United States, National Cancer Institute of Canada. J Natl Cancer Inst 2000;92:205-16.

36. Simon R. Optimal two-stage designs for phase II clinical trials. Control Clin Trials 1989;10:1-10.

37. Yoshida K, Ninomiya M, Takakura N, Hirabayashi N, Takiyama W, Sato Y, et al. Phase II study of docetaxel and S-1 combination therapy for advanced or recurrent gastric cancer. Clin Cancer Res 2006;12:3402-7.

38. Ajani JA, Lee FC, Singh DA, Haller DG, Lenz HJ, Benson AB 3rd, et al. Multicenter phase II trial of S-1 plus cisplatin in patients with untreated advanced gastric or gastroesophageal junction adenocarcinoma. J Clin Oncol 2006;24:663-7.

39. Koizumi W, Narahara H, Hara T, Takagane A, Akiya T, Takagi M, et al. S-1 plus cisplatin versus S-1 alone for first-line treatment of advanced gastric cancer (SPIRITS trial): a phase III trial. Lancet Oncol 2008;9:215-21. 